\title{
Co-creación desde los grafismos en camisetas de los jóvenes de la ciudad de Pereira, Colombia
}

\section{Co-creation from the graphics on T-shirts of the youth of the city of Pereira, Colombia}

DOI: http://dx.doi.org/10.17981/cultedusoc.12.1.2021.10

Recibido: 7 de julio de 2020 Aceptado: 8 de octubre de 2020 Publicado: 14 de diciembre de 2020

Erika María Gómez-Bermeo

Fundación Universitaria del Área Andina. Bogotá, D.C. (Colombia)

egomez2@areandina.edu.co

Edwin Javier Morales-Perdomo

Fundación Universitaria del Área Andina. Bogotá, D.C. (Colombia)

emorales13@areandina.edu.co

Andrés Felipe Roldán-García (i)

Universidad Nacional de Colombia. Manizales (Colombia)

anroldang@unal.edu.co

Para citar este artículo:

Gómez-Bermeo, E.. Morales-Perdomo, E. y Roldán-García, A. (2021). Co-creación desde los grafismos en camisetas de los jóvenes de la ciudad de Pereira, Colombia. Cultura, Educación y Sociedad, 12(1), 151-170. DOI: http://dx.doi.org/10.17981/cultedusoc.12.1.2021.10

\section{Resumen}

El presente artículo muestra un interés particular por la camiseta, prenda de vestir conceptualizada como dispositivo comunicativo. El objetivo es reconocer las significaciones socioculturales y estéticas de los grafismos develados en las camisetas de los jóvenes de la ciudad de Pereira (Risaralda, Colombia), derivadas de las influencias gráficas a las que ellos se encuentran expuestos. Para realizar dicho proceso se emplea el enfoque cualitativo, a través de un abordaje etnográfico para la consolidación de perfiles que reflejan las significaciones del colectivo representado. Los resultados obtenidos indicaron cuatro tipologías: 1) el uso comunicativo por marcas comerciales como prioridad, 2) la preferencia desde pregnancia a la composición de la forma, 3) el uso fundamentado en expresiones musicales, y 4) el uso desde las representaciones políticas. En conclusión, las significaciones de los grafismos de las camisetas se encuentran relacionadas a intereses comunicativos propios del contexto en el que se desenvuelven, sin embargo, los usos de estas prendas no solo están influenciadas por factores externos de consumo, sino también por la necesidad de exponer una realidad social, política o cultural. Los ejercicios de investigación-creación cobran relevancia metodológica, tanto de la obra visual como en el proceso creativo para contribuir a la experiencia transformadora y comunicativa.

Palabras clave: Significación visual; grafismos; estética; camiseta; creación colaborativa

\section{Abstract}

This article shows a particular interest in the t-shirt, a garment assumed as a communication device. The objective is to recognize the sociocultural and aesthetic meanings of the graphics revealed on the t-shirts of young people from the city of Pereira (Risaralda, Colombia), derived from the graphic influences to which they are exposed. To carry out this process, the qualitative approach is used, through an ethnographic approach for the consolidation of profiles that reflect the meanings of the group represented. The results obtained indicated four typologies: 1) the communicative use by commercial brands as a priority, 2) the preference from pregnancy to the composition of the form, 3) the use based on musical expressions, and 4) the use from political representations. In conclusion, the meanings of the graphics of the t-shirts are related to the communicative interests of the context in which they are developed, however, the uses of these garments are not only influenced by external factors of consumption, but also by the need to expose a social, political or cultural reality. The researchcreation exercises acquire methodological relevance, both in the visual work and in the creative process to contribute to the transformative and communicative experience.

Keywords: Visual meanings; graphics; aesthetics; Tshirt print; collaborative creations 


\section{INTRODUCCIÓN}

El presente artículo es resultado de la experiencia investigativa de los autores en los intersticios del diseño, el vestuario y la cotidianidad dentro de las relaciones existentes en la materialidad de los entornos sociales. El principal interés radica en entender las intencionalidades y usos de los estampados develados en las camisetas de los jóvenes de la ciudad de Pereira (Pereira, Colombia), a través de una caracterización simbólica de sus significados. El vestuario es un medio de expresión, todos los objetos que componen la práctica de vestirse hacen parte de ello, de ahí que la moda sea una práctica cultural que responde a las temporalidades. "La moda es un fenómeno cultural y como tal, según Eco, 'es un acto de comunicación', que debe ser explicado mediante los esquemas propios de cualquier acto de comunicación” (Glover, 2017, p. 77).

Dadas las condiciones comunicativas de este fenómeno, surge la necesidad de reconocer lo que sucede con las prendas de vestir, en este caso el objeto de estudio a una sola prenda de vestir: la camiseta, aquella que inicialmente fue utilizada como prenda interior masculina y con el pasar del tiempo sufrió transformaciones que alteraron no solo su estructura, sino sus formas de uso, narrativas y contenidos; transformando los sujetos que la portan.

En la actualidad, la camiseta se crea y re-crea en atención a las tendencias de consumo, Migliaccio (2013) plantea que los consumidores no solo crean significados para los objetos, sino que permiten la construcción de un estilo de vida el cual está inmerso en la generación de significados para sí mismos. Logra que sus prendas construyan tipologías estéticas variadas provenientes de diferentes universos del vestuario. A su vez, alcanza una hibridación que proporciona apariencias cambiantes en diferentes contextos donde el lenguaje es reflejado mediante la adopción de significados relativos a los distintos tipos de vínculos y contextos.

Para la formación en diseño, es importante que el diseñador indague y comprenda las significaciones de los artefactos que propone: "El diseñador contribuye a definir la forma no solo material sino también simbólica (o semántica) de una prenda de vestir y, por tanto, de sus posibles funciones en los procesos comunicativos de la vida cotidiana" (Migliaccio, 2013, p. 368). Estas prácticas fortalecen el interés de los jóvenes universitarios de la ciudad de Pereira (Risaralda, Colombia), por la construcción de los relatos y recorridos representados en los grafismos portados en las camisetas, donde se exploran diferentes materiales, técnicas y soportes en las prendas, permitiendo experimentar y crear discursos con formas particulares de evocar y nombrar la cotidianidad.

\section{REVISIÓN DE LA LITERATURA}

\section{La camiseta como referente histórico}

La camiseta cubre el cuerpo no solo desde un aspecto funcional, sino que posee cargas simbólicas susceptibles de ser analizadas desde la relación entre vestido, cuerpo y contexto. El sujeto en la práctica de vestirse se involucra en la construcción de su apariencia frente al otro, es decir, se viste para aparecer ante los demás, como indica Entwistle (2002): "La ubicua naturaleza del vestido parece apuntar al hecho de que la ropa o los adornos son 
uno de los medios mediante los cuales los cuerpos se vuelven sociales y adquieren sentido e identidad" (p. 12).

Se prepara el cuerpo para dicha práctica cultural contextualizada, toda vez que el sujeto manifiesta diversas intencionalidades, desde cuando se expone ese cuerpo vestido hasta el momento en que se encuentra en su espacio privado; el vestuario es habitado y practicado mediante un cuerpo que se prepara distinto en relación a los espacios e intenta habitarlos de forma diversa, como propone Merleau-Ponty (citado por Entwistle, 2002): "Nuestro cuerpo no está en el espacio como las demás cosas, sino que lo habita o lo frecuenta" ( $p$. 5). Esto implica que la noción de corporalidad está sujeta a la carga intencional con la que disponemos lo que usamos. Bajo la propuesta de Goffman (1959), se entiende que el sujeto busca conquistar dicho espacio a través de diferentes estrategias de vestuario, reconociendo la corporalidad desde la intención de transgredirla, alterarla, modificarla o brindar algún sentido, desde el vestuario dispuesto en un espacio determinado.

En los años 60, la camiseta fue considerada una prenda de vestir perteneciente al universo del vestuario jeans y sport wear, precedida en los años 50 por una cultura juvenil que quería empezar a diferenciarse de los adultos desde su vestuario y construir estéticas propias que enfatizaban su actitud de desinterés por la alta costura, apostándole a un imaginario de juventud y construyendo sus propios signos legítimos de distinción (Lipovetsky, 1990).

Múltiples prácticas estéticas de la época dan cuenta de la intencionalidad comunicativa de trasgresión a los paradigmas convencionales: la música, el arte, el diseño, el vestuario entero, se convierten en referentes de alteridad al orden elitista establecido. Algunas de estas transgresiones están en el cine, donde se muestran las cargas comunicacionales que los jóvenes querían representar en el imaginario de juventud en determinada época, así como los factores sociales y culturales que envolvían dichas prácticas. "Rebelde sin Causa" (1955), es una película del director Nicholas Ray y es uno de los films que reaccionaron a los comportamientos y prácticas de la rebelión juvenil de los años cincuenta en Estados Unidos; su protagonista James Byron Dean es una muestra clara de un sujeto generador de tendencia en cuanto a la actitud corporal, a la manera de cómo su cuerpo portaba el vestuario y se apropiaba del espacio. "El actor se convirtió en un ícono por su papel de rebelde que fumaba y vestía vaqueros, camiseta blanca y cazadora roja" (Muller, 2008, p. 334).

Para las últimas décadas del siglo pasado, algunos íconos representativos de la moda comunicaban a través del uso de estas prendas un mensaje de rebeldía que rompía esquemas tradicionales; la imagen icónica de James Dean, con camiseta blanca ajustada al cuerpo, configuraba un patrón comunicativo de libertad ante los volátiles contextos políticos y sociales. En este contexto, la camiseta, una prenda básica, deja de ser un objeto funcional o laboral para convertirse en una prenda cargada de significaciones de juventud, expresiones de identidad y estados mentales que refuerzan dicha actitud.

\section{La Camiseta: Un dispositivo para la comunicación y el lenguaje}

La camiseta como una expresión estética de trasgresión social logra una mayor trascendencia comunicacional cuando sus contenidos, evidenciados en grafías o imágenes 
se constituyen como parte fundamental de la prenda. Inicialmente la identificación del fabricante resultaba en una recordación de marca, situación que posteriormente se usó para fines publicitarios, suceso que transformó la prenda rápidamente en un contenedor comunicativo; no solo dice de quién y cómo la usa, sino que es en sí misma una valla itinerante, un dispositivo que habita múltiples espacios por los trayectos trazados de quien la usa. La camiseta trasciende de la imagen o el texto que se encuentra impregnado en su superficie, es decir, se convierte en un objeto social, político, expresivo, dinámico e interactivo.

Las grafías o imágenes contenidas en la camiseta resultan para los sujetos en la posibilidad de manifestar sus diversas intencionalidades comunicativas, tal como lo plantea Entwistle (2002), "vestirse es un logro técnico y práctico que se funda en el conocimiento social y cultural acumulado" (p. 41). Y es en ese conocimiento acumulado en donde los sujetos emplean la imagen adherida a la camiseta como signos legítimos de distinción o expresión, como manifestaciones de su identidad.

Esta dimensión de la camiseta como un artefacto comunicativo que transporta y lleva consigo una o varias imágenes resultando en una valla itinerante, ha sido a través del tiempo partícipe de las prácticas vestimentarias que se relacionan con la moda, adherida bajo las posibilidades técnicas de cada época. Una de ellas es la serigrafía, definida según Sanjurjo (2001) como "reproducciones de textos e imágenes sobre soportes adecuados, de modo que la imagen a imprimir entintada se oprime sobre el material a imprimir y con ello se forma una "imagen impresa" por la transferencia de la tinta al soporte" (p. 85).

La técnica de serigrafía se ha implementado a partir de diversas tintas en el textil, tales como el plastisol, base agua, y actualmente a través de la tecnología se han ido adaptando las tintas a las características, composición y color de cada base textil, buscando cada vez más la posibilidad de mejorar la calidad visual y táctil el grafismo. Otra técnica de intervención en las camisetas ha sido el teñido en tie-dye (por amarre y reserva), como lo realizaban los jóvenes en los 60's, o posteriormente, con la facilidad de acceder a procesos de transferencias de tintas a través del transfer, sublimación e intervenciones manuales, que son frecuentes en la actualidad. Esta búsqueda permanente por mejorar la técnica evidencia una preocupación por la forma y el desarrollo de la prenda, un interés por la imagen contenida en la camiseta, una oportunidad para la construcción de discursos narrativos por parte del sujeto que la produce, exhibida por el sujeto que la porta y apropiada al involucrarse con el contexto.

El sujeto como portador de imágenes orbita entre objetos y situaciones que le invitan a entablar juegos de aproximaciones con su cotidianidad y con el otro, relaciones a través del lenguaje. Según Trinidade y Da Silva (2009): “Todos los abordajes teóricos sobre la imagen tienen como fondo el hombre como su productor e intérprete. Manifiesta la dimensión del producto humano en el seno de las culturas" (p. 214); lo que nos invita a pensar que la imagen es un dispositivo cultural que tiene como accionador y accionado al sujeto, dentro de una relación de mutua afectación.

Además, se permite construir un orden de dominio sobre lo que aparece o, mejor, acontece frente a él, pues cuando emplea el lenguaje se orienta, clasifica y da sentido a los múltiples y diversos fenómenos que hacen parte de su vida cotidiana y que puede proyectar 
en su indumentaria, en este caso es lo que expresa en las camisetas que porta, ya que el vestuario resulta una exterioridad material de su identidad y pensamiento. El desarrollo del lenguaje es inherente al desarrollo de la vida social, pues las palabras y las imágenes, con sus matices, contribuyen a expresar los estados afectivos, los pensamientos de la colectividad y de interés mutuo. El lenguaje cumple así la función de mediación entre el sujeto y el mundo, una aproximación a la esfera de lo social.

La relación establecida entre el individuo y el grupo es la característica que fundamenta el comportamiento estético. Para Leroi-Gourhan (1965), la etnia es entendida como comunidad humana definida por afinidades raciales, culturales, lingüísticas, entre otras, invita al sujeto a una inserción afectiva en su sociedad, desencadenando procesos de exteriorización, que abonan el camino para lo que el mismo autor llama código de las emociones. Dentro de ese comportamiento estético se da prelación a la percepción de los valores y los ritmos presentes en el seno del grupo, intelectualizando progresivamente las sensaciones para establecer símbolos que, con el paso del tiempo y en un acuerdo consensuado, pasan a tener una significación colectiva. Estas apreciaciones llegan a formar parte de lo que conocemos como cultura, en la que los valores de uso y funcionalidad que ofrecen los objetos dispuestos en la realidad desembocan, para quien se detiene en sus componentes, en una apreciación estética de las formas.

\section{Tipologías analíticas de los significados en las camisetas}

El sujeto puede crear, re-crear, interpretar, aceptar o alterar la realidad de su entorno a partir del uso y manipulación del lenguaje visual (gráfico y textual) reflejado en una prenda de vestir como la camiseta. Alterar de algún modo la significación de las palabras a través de sus figuras, complementar imágenes e invertir el sentido de los mensajes, tomando el efecto por causa o viceversa, el signo por el significado, o aplicando una alegoría para apropiarse de algunas palabras en sentido literal y otras en sentido figurado. Estas prácticas constituyen manifestaciones creativas del lenguaje en el escenario del vestir.

La utilización del lenguaje como recurso de construcción estética intencional complementa el mensaje en las camisetas, sin dejar de lado la significación visual que carga la imagen; estos elementos se exhiben públicamente, en la práctica cotidiana del vestir, en tanto reflejo fiel de la interacción que cada individuo asume con su entorno. Además, dadas las circunstancias que permiten la comunicación de dichos mensajes "la necesidad de autoexpresión y la preferencia por determinadas marcas dependen de la disponibilidad de medios alternativos de autoexpresión. Así, por ejemplo, comportamientos auto-expresivos como la personalización de los productos, pueden llevar a generar identidad en el consumidor" (Onofre-Chaves, 2017, p. 57).

Generalmente, cuando se habla a través del vestuario se observa que algunos sujetos emplean metáforas, re-elaboraciones de conceptos e ideas que permiten entablar un juego con el otro a partir del uso del lenguaje, prácticas en las cuales las camisetas se traducen en variaciones cargadas de nuevos significados en el uso. Vestir resulta de un acto consciente en el propósito de adaptación del sujeto al entorno, pero también, constituye una práctica significativa del habitar. 
Para la identificación de las tipologías se tuvieron en cuenta dos de las tres categorías planteadas por Hernández (2006) en la cual propone una exploración hacia los horizontes del análisis de dato visual; la primera es el ilustrativo y la segunda el análisis de intencionalidad.

\section{- Ilustrativo}

"Las imágenes en los textos son referidas como argumento. En lo audiovisual la imagen se utiliza para acompañar un discurso" (Hernández, 2006, p. 10). En el caso del presente proyecto esta categoría se fragmenta en dos posibilidades, la primera es lo ilustrativo como argumento de uso de logos y marcas comerciales y la segunda como argumento de construcción del lenguaje cotidiano, como fue mencionado anteriormente.

\section{- Análisis de intencionalidad}

El autor-lector (en un proceso intersubjetivo y comunicativo). Esta intencionalidad se planteó desde la sensibilidad hacia diferentes prácticas de filiación cultural como la música, la estética y la política entre otras.

\section{Tipologías de análisis}
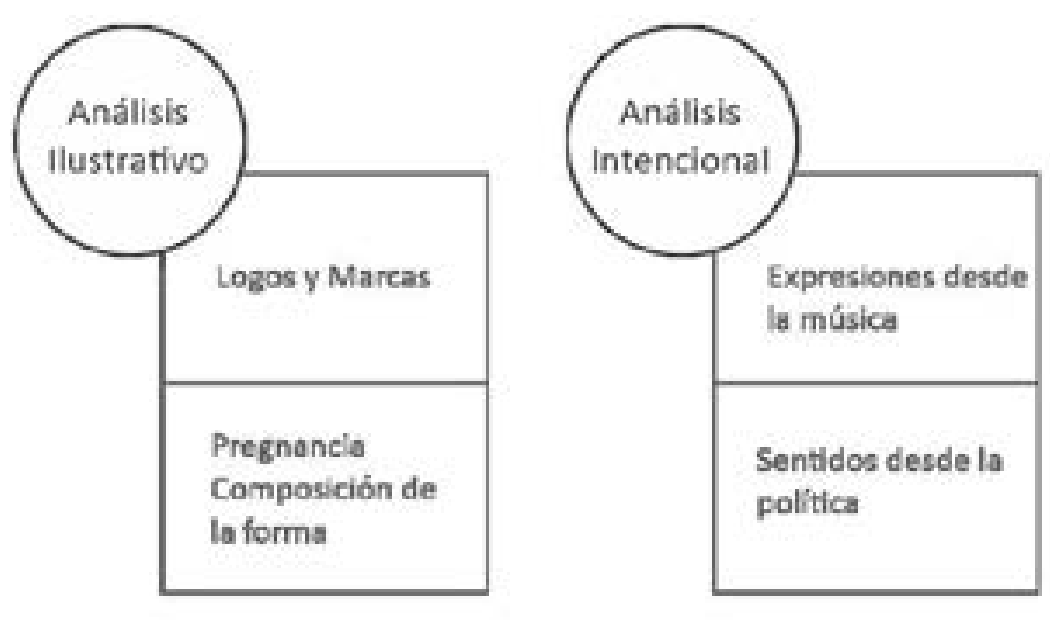

Figura 1. Esquema de análisis para la investigación.

Elaboración propia.

Las tipologías de análisis y las subcategorías propuestas responden a las prácticas y expresiones socioculturales más recurrentes en la construcción de significados estéticos dentro de los hallazgos, y a pesar de existir muchas otras categorías, fueron las tipologías analíticas reiterativas en el trabajo de campo y en la configuración de sentidos de las imágenes y grafías del vestuario analizado (Figura 1).

Desde el análisis ilustrativo, se tuvo en cuenta la marca como función simbólica, pues según Iglesias (2015) una marca trasciende más allá de la estructura formal de los productos que vende, por lo tanto, está construida a partir de imaginarios ligados a valores que permiten una construcción de identidad personal al ser adquiridos por quien consume 
la marca, "(construcción de autoconcepto o identidad personal) o cuando este consumo o uso del producto se hace como carta de presentación en el teatro de la vida cotidiana construyendo así la identidad social" (Goffman, citado por Iglesias, 2015, p. 284). La siguiente categoría del análisis ilustrativo es la preferencia desde pregnancia a la composición de la forma, allí se analizaron las relaciones afectivas del objeto (camiseta) con el sujeto, ya que según Mandoki (2006) dentro de la estética de la vida cotidiana existen matrices que pueden seducir al sujeto estéticamente, para generar pregnancia “[...] de ahí la función primordial de la estética para lograr esa identificación al reclutar la disposición afectiva y sensorial del sujeto hacia el prendamiento" (Mandoki, 2006, pp. 74-75).

Pasando a las dos categorías restantes que hacen parte del análisis intencional, las expresiones desde la música se observaron teniendo en cuenta la importancia del discurso que dicha práctica contiene. Como plantea Carballo (2011), la música posee un "discurso de la visión de mundo de un sujeto sobre un tema en concreto, y esta visión, al ser socializada, es asumida por otros que al escucharla encuentran algún nivel de coincidencia con el planteamiento" (p. 1342); y todo ello se refleja en filiaciones no solo acústicas sino estéticas desde la apariencia, el baile, la corporalidad entre otros. Finalmente, la categoría de los sentidos desde la política se basó principalmente en las expresiones generadas por el pensamiento político que "se basa esencialmente en la capacidad de juzgar. Gracias al juicio, la persona se reconoce y establece afinidades o distancias con otros" (Lozano y Alvarado, 2011, p. 105); y dichos pensamientos, se observaron desde acciones exteriorizadas en objetos cargados de sentidos, en este caso los grafismos que portan en sus camisetas.

\section{Metodología}

El artículo se fundamenta en un enfoque cualitativo, de orden etnográfico. Se privilegió un grupo humano específico en la ciudad de Pereira (Risaralda, Colombia), los cuales tuvieran atributos significativos en la construcción de su apariencia. Es decir, la investigación seleccionó varias tipologías juveniles en las cuales se representaran de manera sistemática expresiones estéticas particulares.

Es de anotar que la investigación cualitativa etnográfica permite establecer miradas a grupos sociales particulares, lo que permitió caracterizar la población y construir matrices de análisis comportamental, por lo tanto, se determinó esta metodología para posteriormente seleccionar la población objeto de estudio, tomando en cuenta variables interpretativas por diferentes grupos.

La mirada etnográfica permitió identificar varios grupos y subgrupos juveniles, en los cuales se priorizaron, los que tenían cargas significativas estéticas más relevantes, es decir, se analizaron varios grupos etarios y sociales, seleccionando a quienes lograron instalar en las representaciones de sus camisetas patrones estéticos predominantes o reiterativos. El contexto analítico abordado, permitió identificar varios escenarios sociales de incidencia, por grupos juveniles, es decir, el uso de camisetas y sus grafismos intencionales, predomina más en jóvenes universitarios, debido a que habitan escenarios de construcción libre de vestimenta, pero regidos por reglas de convivencia institucional. Los jóvenes universitarios tienen obligaciones académicas, tensiones sociales y expresiones identitarias en un mismo lugar, de allí la importancia de su elección en la investigación. 
Se realizó un registro fotográfico periódico que permitiera documentar las diferentes manifestaciones gráficas con el propósito de determinar la estética de las camisetas de los estudiantes, priorizando las grafías desde el espectro artístico y comunicativo. Posteriormente, se realizó un registro fotográfico al detalle que ordenó la información según los contenidos de los estampados de las camisetas, mediante un análisis visual que relacionaba contenido textual, imagen, ilustración y mensaje (Figura 2). Pese a la variedad de la muestra los resultados arrojaron categorías de estudio que delimitaron la investigación, entre las que se destacan: la prioridad por la marca de la prenda, el mensaje político, las formas y figuras y las preferencias personales.
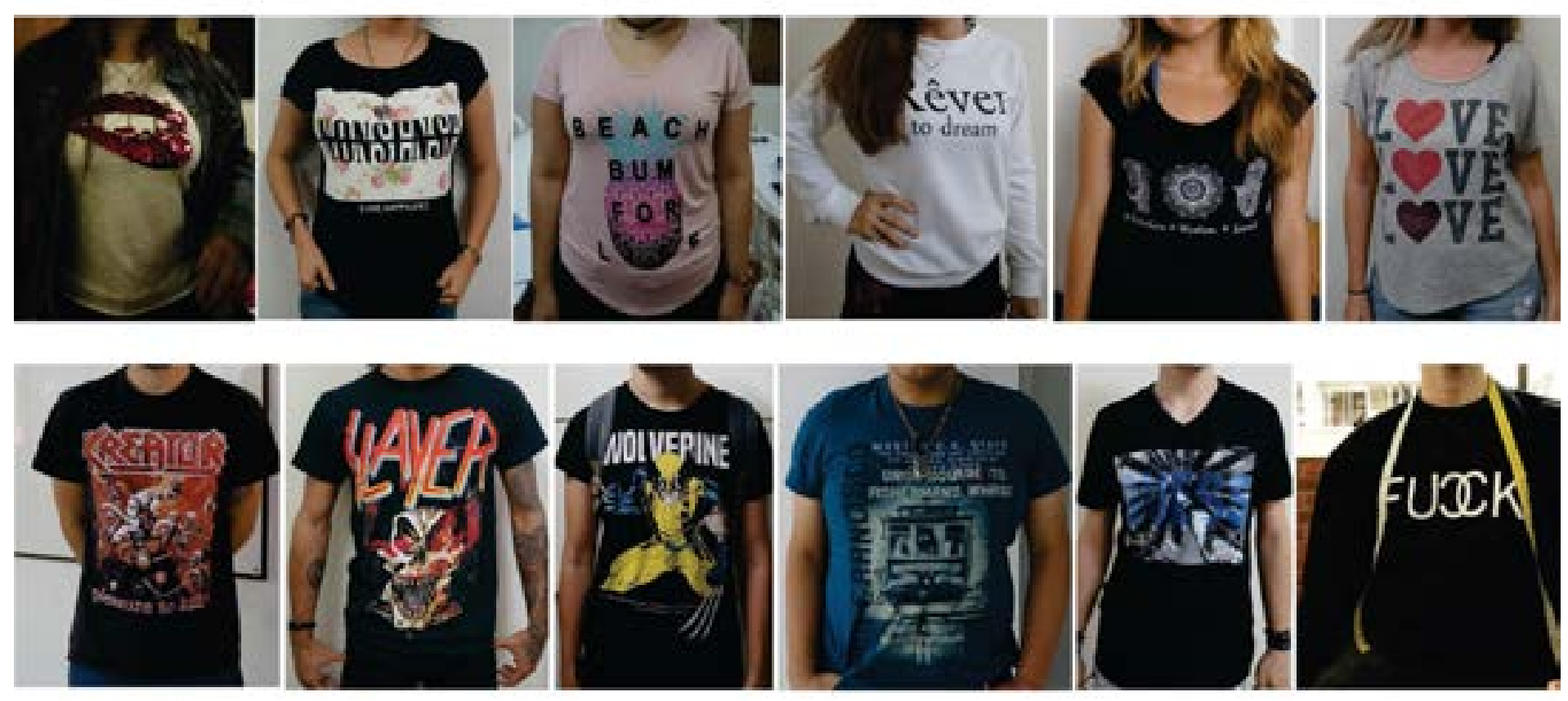

Figura 2. Registro fotográfico de las camisetas en uso. Elaboración propia.

Tras haber realizado una categorización de los sujetos que hacen parte del grupo de estudio se seleccionó un sujeto perteneciente a cada una unidad de análisis planteado y se realizaron entrevistas abiertas, con procesos de observación del espacio privado (sus habitaciones) generando contenido audiovisual de las trayectorias de cada sujeto.

El análisis correspondiente permitió caracterizar el uso de los grafismos develados en las camisetas desde diferentes trayectos: el primero es el entorno social, que posibilita establecer estructuras concebidas por grupos que denotan especificidades y el segundo, desde prácticas culturales que se desarrollan en las categorías de análisis expuestas. Dicho análisis implica que tanto el carácter ilustrativo enunciado, como el carácter intencional de los significados en las camisetas a través de la población abordada, integran un universo de representaciones estéticas múltiples en el universo social de la representación y cultural de la identificación. La información se filtró mediante una estrategia de afinamiento de los registros, que inició con un análisis morfológico, seguido de un análisis de contenido y por último un ejercicio de significación (análisis de intencionalidad) que involucró a los usuarios tipo. Las categorías de estudio se derivaron de las variables que el contexto arrojó. 


\section{RESUltados}

A continuación, se describirán los resultados de la investigación, las tipologías comunicativas que responden al criterio de intencionalidad y reiteración en el uso del grafismo. Estas cuatro tipologías son, La marca como prioridad (I), Preferencia desde pregnancia a la composición de la forma (II), La música como intencionalidad del proceso comunicativo (III) y La política como intencionalidad del proceso comunicativo (III).

El análisis de los registros y la identificación de las categorías dejó en evidencia cómo el significado de los sentidos socioculturales que se le atribuyen al uso de las camisetas, varía de acuerdo a múltiples contextos y factores, es decir, no siempre el uso corresponde a una intencionalidad comunicativa específica, ya que los usos pueden corresponder a factores exógenos a la elección subjetiva, factores sociales, económicos, entre otros. Es así como se develaron los grupos poblacionales en los cuales se identifica el uso de grafismos intencional y constante en sus camisetas, cuyo contenido comunicativo era reiterativo y con significados explícitos, donde la camiseta se convierte en un contenedor expresivo público.

Las tipologías que de allí se derivaron fueron:

\section{La marca como prioridad (I)}

La construcción de elementos analíticos ilustrativos da cuenta de expresiones visuales, configuradas a través de figuraciones explícitas del lenguaje, son las caracterizaciones de uso ligadas a lo que se enuncia en el uso de la prenda, en este caso de la camiseta. El carácter ilustrativo se instaura en el universo de la descripción y la enunciación de la imagen o los elementos de contexto o forma que expresa la imagen en su disposición. El uso de camisetas con imágenes de marcas se convierte en un referente de distinción y adhesión social, el cual posee niveles de afectividad con marcas reconocidas en el mercado, las cuales potencian sus imaginarios de consumo en el posicionamiento de sus aspiracionales.

Este posicionamiento social es tan alto que logra que el sujeto asuma la exhibición de los logos de dichas marcas estampados generalmente en la parte frontal de la camiseta, como acumulación de capital. Según Bourdieu (2006), al portar las significaciones de cada marca el sujeto quiere evidenciar inicialmente que tiene la posibilidad socioeconómica de adquirir la camiseta al precio en que la marca la vende en el mercado, y en efecto se puede evidenciar que el logo y lo que representa la marca son signos legítimos de distinción.

Es en este contexto, donde la imagen como argumento que acompaña el discurso de una marca, recurre a sujetos con un alto poder de influencia, como músicos, influencers, cantantes de TRAP ${ }^{1}$, los cuales no solo muestran la marca como signo legítimo de distinción en sus camisetas, o en redes sociales, sino que la explicitan en sus videos musicales y letras de canciones. Tomando como por ejemplo: "Tu compras todas las Jordan bobo, a mí me las regalan. Trato de hacer dieta, pero es que en el closet tengo mucha grasa. Ya mudé la Gucci pa dentro de casa" (Cardi B, 2018, 1m 38s), también se puede observar en la siguiente canción "Yo soy boquisucio como Luigi. Nunca fake, siempre origi. Claro, como Agua Fiji, yeah. Y esa camisa tuya la mandaste a hacer, Que fui a la Gucci y en la tienda no la pude ver (jaja). Tu flow es piratea'o, medio descontinua'o" (Arcangel, 2018, 2m 10s).

\footnotetext{
1 Trap: Sub Género musical del Hip Hop.
} 
Este sector específico de la población sujeto de estudio muestra etapas de fidelidad a las marcas que son usadas y promocionadas por los sujetos de alta influencia, de acuerdo a los momentos de la moda, pueden ser efímeros o permanentes, todo depende del ritmo del cambio de los influenciadores. Así mismo, los comportamientos de consumo se influencian por las prendas que utilizan los artistas del momento y por las variaciones que estos tengan en determinada época, asumidos por grupos específicos en los cuales existe una intención marcada de pertenecer o diferenciarse, situación muy marcada por sus exterioridades materiales: los objetos que se porten y las prendas que se usen.

Los miembros de este grupo se autodenominan observadores y están atentos de las publicaciones realizadas en las redes sociales, así como afirma un joven entrevistado (19 años), que menciona:

Aparte de que a uno le gustan las camisetas con el logo, son marcas que tienen trayectoria, las telas son finas y además por las redes hacen publicidad, utilizan gente de la farándula y uno (así lo niegue) las usa para verse como ellos, para aparentar que tienen como plata. Además, uno piensa que si las celebridades lo usan es porque es el mejor producto.

Este grupo valora el producto, paga el precio y porta las marcas comerciales en sus camisetas como valla itinerante, respeta tanto el valor de la marca que se asume parte de ella y por consiguiente no se permite utilizar una réplica o copia, prendas de fácil acceso en el contexto pereirano, donde se puede evidenciar su comercialización en diversos sectores comerciales no oficiales y a precios muy bajos. Tal como lo menciona el entrevistado, al decir:

A mí me da pena usar réplicas porque uno conoce y sabe que la gente se va a dar cuenta, son estampados feos, yo no sé por qué no soy capaz de ponérmela, ni las lociones "chiviadas", o uno será muy lámpara².

Esta relación con las marcas en las camisetas tiene entonces una importante carga social, la cual da cuenta de cómo el usar el referente de un logo, se remite a la legitimación de este y la distinción que implica el llevarlo, es una práctica de referencia análoga de emulación a un producto o marca que considera instaura una validación o estatus al usarlo.

\section{Preferencia desde pregnancia a la composición de la forma (II)}

El lenguaje cotidiano en el uso de las camisetas tiene para algunos grupos poblacionales una implicación formal, en la cuales los elementos de estructura tienen más valor significativo, que los elementos narrativos. Esto implica un uso de la camiseta y el vestuario en general desde intereses de pregnancia o adherencia a la composición de la prenda en texturas, formas, materiales, colores, etc.

Es en estas prácticas donde la imagen en el vestuario acompaña un discurso cotidiano, en el que se tiene en cuenta la construcción de las imágenes y palabras desde la composición misma, y desde las tendencias de consumo visual en el contexto provenientes de las marcas generadoras de tendencia a nivel mundial. Por lo tanto, se valoran los elementos compositivos de la tendencia, tales como el color, la tipografía y la morfología de las imágenes. Al

\footnotetext{
${ }^{2}$ En el lenguaje cotidiano es sinónimo de ostentoso, persona que busca llamar la atención, o es muy popular.
} 
grupo de estudio no les interesa si contiene textos en otros idiomas, tales como el inglés, ya que en este rango etario se está en contacto con otros idiomas, a diferencia de algunos casos, donde prima la forma por encima que el contenido, por ejemplo: Pueden portar un estampado en otro idioma, sin saber que traduce al español, tomando el riesgo de exhibir un discurso al cual no tiene ninguna filiación, tal como lo menciona uno de los entrevistados:

Cuando voy a comprar una camiseta estampada, primero miro el color de la prenda, pues que me guste, segundo miro los estampados que me parecen chéveres, y si alguno me gusta de una lo compro, no me pongo a mirar si está en inglés o en español, más bien pienso con que me puede combinar, con más de una pinta.

Resulta importante para este grupo estar al tanto de lo que sucede en el mundo en cuanto a imágenes, texturas, bordados y estampados, no impera necesariamente el precio de la prenda, ya que no son fieles a las marcas, más bien consumen de acuerdo a la conexión inmediata que la prenda genere en ellos, esos tres segundos iniciales en los cuales la decisión de compra se toma a partir de la emoción del momento.

En esta construcción cotidiana se relaciona el uso de la prenda con impresiones inmediatas, que trascienden el uso comunicativo, como lo es la composición general, ver la prenda y adquirirla por un gusto en su estructura. Se prioriza la forma, la composición, el color y los elementos materiales para su uso, pues se considera que la camiseta es un elemento cotidiano y recurrente, por lo tanto, el efecto comunicativo no es una prioridad.

\section{De la música hasta la política: Intencionalidades socioculturales}

Otras formas de uso de la imagen en las camisetas encontradas durante la caracterización del grupo objeto de estudio, se enfocan en la intencionalidad del proceso comunicativo a partir de una filiación cultural, en ese sentido se establecieron dos categorías que fueron ampliamente evidenciadas: la música, y la política. Entendiendo la práctica de la comunicación como un proceso de relaciones recíprocas entre sujetos, que se relacionan a su vez con otros sujetos, para construir sentido social y generar afectaciones (a favor o en contra).

\section{La música como intencionalidad del proceso comunicativo (III)}

Dentro de esta categoría, podemos ubicar aquellos usuarios de las camisetas quienes comunican de manera explícita su adhesión o gusto por un género musical o artista específico. Pese a que esta práctica es común y se encuentra en todas las esferas musicales, para el marco del contexto analizado es recurrente las prendas con componentes comunicativos derivados de identidades musicales hacia el género rock y en particular al metal.

Muchos de los usuarios analizados portan las camisetas de las bandas de música de géneros que van desde el Hard rock, Speed Metal, Thrash metal (ambos subgéneros del Heavy metal), hasta el Brutal death metal $^{3}$, los cuales siguen por un proceso cultural de identificación con sus gustos y preferencias. La música hace parte de su cotidianidad, más allá de ser una forma de expresión, puede entenderse como una estrategia de introspección que toma los sentidos a partir del estado de ánimo del sujeto para satisfacer deseos de

3 Subgénero musical del death metal. 
escape, de desconexión, de desintoxicación y vivir momentos hápticos que repercuten en la cotidianidad. Si bien, la música puede ser escuchada, también puede ser palpada, puede tocar el cuerpo a través de los sentidos, y cuando ese cuerpo es tocado surgen experiencias estéticas cargadas de significación, en las cuales se afirman las filiaciones a dichas bandas musicales.

Los sujetos caracterizados en esta categoría procuran coleccionar camisetas de cada concierto al que asisten, en las cuales llevan estampados referentes a las bandas protagonistas del espectáculo, como demostración de fidelidad y evidencia de los encuentros cercanos con sus ídolos. Dichas prendas pueden ser compradas en el lugar del concierto, en sus inmediaciones o antes del evento en centros comerciales o tiendas especializadas en esta tipología de prendas. Tal como lo afirma uno de los jóvenes entrevistado:

A mí me gusta coleccionar las camisetas de cada concierto que voy, pues es como algo personal, como mirarlas y recordar cada concierto, y ponerme la meta de ahorrar para poder ir al siguiente concierto. También me gusta mostrarles a los amigos que entran a mi casa, no sé, es algo que me hace sentir como plena, y la verdad uno como que también compite en silencio por el que más camisetas tenga.

Un fenómeno evidenciado en estas camisetas de colección, es que pasan de ser una tipología de prenda de vestir específica con características morfológicas de mayor comodidad, a ser objetos de valor con significaciones especiales representativas no solo de una banda musical, sino un momento vivido, ese momento en que se pueden percibir experiencias estéticas. La puesta en escena de los artistas, el espectáculo que implica ver las interpretaciones musicales en vivo, constituye un escenario perfecto donde entran en juego el entramado de sentires desde el tiempo, el cuerpo, el colectivo y el espacio alrededor de un grupo musical esperado incluso por periodos de tiempo prolongado.

La imagen plasmada en estas camisetas son representaciones de momentos, constituyen un testigo silencioso de la cita musical a la que se asistió y estos estampados generalmente cubren en un porcentaje muy alto la parte frontal o posterior de la prenda. A menudo están realizados en policromías para darle mayor realismo a la imagen y como factor común predomina el color negro en la base textil. Algunas de estas características dan cuenta que la intencionalidad comunicativa es explícita y pública, busca tener un impacto visual más directo, identificable fácilmente y cuya adhesión estética se encuentre relacionada directamente con la adscripción cultural que se posee.

Así mismo, existen muchas otras adscripciones musicales en el uso de prendas tipo camiseta, en las que se incluyen todo el universo de identidades y gustos musicales existentes. No obstante, se mencionó específicamente el género musical del Metal, pues fue una expresión visual recurrente y que en el contexto de la investigación realizada tenía formas y elementos comunicativos explícitos, cuyo orden disuasivo es esencialista, buscando comunicar de manera directa la identidad musical de quien la porta.

\section{La politica como intencionalidad del proceso comunicativo (IV)}

La política tiene múltiples definiciones, pero en esencia se concibe como todos los actos humanos encaminados a la convivencia armoniosa dentro de una comunidad organizada en la búsqueda de un bien común. Para Aristóteles (1873), la política es una actividad 
inherente a la vida humana dado que el hombre por naturaleza es un ser político, es decir, un ser social que necesita vivir en comunidad y el principio básico es el bien común, entendiendo las diversidades para aprender a vivir juntos.

Por lo tanto, los estampados en las camisetas con contenidos políticos son tan variados como los alcances mismos de la palabra, no obstante, aquí relacionamos fundamentalmente a quien da un uso de expresión política alterna o cuya esencia comunicativa es disuadir ante un orden establecido. El uso de las camisetas con contenidos políticos a excepción de periodos electorales o funcionarios con adscripciones institucionales quienes usan la marca como una forma de señalar su pertenencia formal, se presenta en situaciones de trasgresión o persuasión ante posicionamientos políticos determinados, la camiseta se convierte no solo en un mecanismo de filiación, sino en un contenedor comunicativo de una expresión o postura particular.

En este universo de la comunicación política a través de mensajes en camisetas, encontramos las marcas de vestuario emergentes, emprendedores jóvenes que buscan suplir imaginarios a partir de contar en la diagramación de una frase o palabra lo que ocurre en los contextos, políticos, sociales, culturales y ambientales, pero que siempre pretenden persuadir de manera implícita o explícita a quien usa la prenda y a quién la ve.

En los usuarios analizados se evidencia reiterativamente que este tipo de camisetas ha venido surgiendo a partir del comportamiento crítico de los jóvenes que hacen parte o que representan la denominada generación "Z"; dicha generación es nombrada de diversas maneras, una de ellas es "post-millennial". De acuerdo a investigaciones de expertos en marketing, investigadores y analistas de mercados se plantea que pertenecen a la generación “Z”, los nacidos desde mediados de los 90 hasta el 2010 aproximadamente. Estos sujetos crecieron con recordatorios constantes de que está bien o que está mal, son jóvenes que traen la indignación de la mano y piensan que a partir de pequeñas prácticas se puede cambiar el país y el mundo. Podemos describirlos como se menciona en el artículo del World Global Style Network (WGSN, 2016):

Definidos por un mundo post internet, los miembros de la Generaciones Y y Z son expertos en la alta velocidad, lo móvil y lo digital. Uniendo esta sensación de conectividad con la necesidad humana por protestar y manifestarse, obtenemos una idea del alcance potencia de esta nueva generación de activistas.

Estos jóvenes, sienten la necesidad de develar constantemente las injusticias o malas prácticas que ven en su entorno regional, nacional o mundial, y la imagen plasmada en los estampados que utilizan en la cotidianidad son una herramienta de denuncia o pronunciamiento, de mostrar lo que piensan, con un lenguaje crítico, consciente y en ocasiones fuerte.

En este escenario la prenda tipo camiseta se convierte en objeto comunicativo desde el contenido simbólico de sus estampados mostrando su optimismo con la necesidad de hacer algo para que las cosas mejoren o mostrando su inconformidad ante situaciones de afectación que no comparten. En muchos casos el uso de las camisetas se refiere permanentemente a imaginarios de sensibilidad colectiva que se plasman en prendas individuales. 


\section{DiSCUSIÓN Y CONCLUSIONES}

Los jóvenes de la ciudad de Pereira (Risaralda, Colombia) encuentran en los mensajes estampados en sus camisetas un recurso de exteriorización para sus preferencias, gustos, pensamientos e inconformidades, convirtiendo la prenda en un dispositivo social de comunicación. Dichos mensajes contenidos en las camisetas se enmarcan según el rango de edad, en intereses comunicativos o significativos propios del contexto en el que se encuentren. El universo de significación en que estos jóvenes enmarcan sus prácticas del vestir no solo es influenciado por las redes sociales, las tendencias de consumo globales, la incidencia de las marcas y las recomendaciones tácitas o explícitas de las figuras públicas, sino que también por las formas de persuasión desde la construcción de sentido de su realidad social, política o cultural.

Las construcciones simbólicas del vestir y específicamente de las prendas tipo camisetas son derivadas de los elementos del lenguaje gráfico que circunda los usuarios. Sus interacciones informáticas, redes sociales, entornos universitarios y contextos regionales, marcan pautas claras de estilos, estéticas determinadas en la búsqueda de la identidad. Los grafismos y las significaciones que le corresponden a los estampados de las camisetas, constituyen en gran medida prácticas cambiantes que reflejan los intereses de grupos poblaciones dentro de la sociedad, por lo tanto, son dinámicas altamente volátiles que se encuentran en permanente transformación.

Desde la co-creación como el recurso de síntesis y tras realizar un acercamiento a los entornos próximos de los usuarios tipo, conocer sus habitaciones, gustos musicales, preferencias y aspiraciones, así como sus publicaciones en redes sociales y sus prendas de vestir, se logró caracterizar de forma detallada los grupos a los cuales pertenecen y las implicaciones simbólicas y estéticas que se derivan de la influencia gráfica de los jóvenes participantes. La información analizada, permitió configurar los universos de cada grupo caracterizado, los cuales fueron representados por un sujeto específico o usuario tipo, quien reúne las características del grupo como tal, para permitir en el proceso de creación, desestructurar y posteriormente configurar en la amalgama de grafismos procesos nuevos de ilustración análoga y digital que representen al grupo.

Dicho proceso de ilustración se enmarca en prácticas de co-creación en las cuales el docente con los estudiantes, en su mayoría pertenecientes al semillero de investigación del proyecto, exploraron técnicas gráficas, estructuras de mensaje y temáticas que permitieron evidenciar mediante creaciones visuales la síntesis de los hallazgos obtenidos. La información recolectada con la ejecución de las diferentes fases del proyecto permitió delimitar el fenómeno de estudio en un conjunto de elementos físicos, técnicos, simbólicos, estéticos y de lenguaje que estructuraban la compleja red de contenidos visuales de los que se componen los estampados de las camisetas. Las significaciones y los universos simbólicos resultan de las relaciones existentes entre cada uno de los contenidos y las posibilidades discursivas derivadas, la práctica simultánea del vestir, el significar y el representarse. 
Los docentes, estudiantes y participantes del proyecto expresaron sus ideas y reflexiones frente a los datos obtenidos y plasmaron mediante un ejercicio colaborativo de creación, un collage visual que reúne y sintetiza las significaciones encontradas como parte del análisis. La co-creación, tal como lo menciona Santaella (2006), permite el desarrollo escalonado de competencias individuales a partir del trabajo colectivo, un aprendizaje permanente de los participantes, significaciones compartidas y estéticas expandidas del saber colectivo.

Sanders y Stappers (2008) proponen el término co-creación para referirse a la creatividad colectiva resultante de un proceso compartido entre dos o más individuos creativos. Es en este escenario donde la práctica creativa propuesta tiene lugar como un ejercicio que propende por la multiplicidad de perspectivas, la variedad argumentativa y los aportes individuales a la construcción del imaginario colectivo. Las técnicas usadas vincularon el dibujo análogo con los medios de expresión digital en una fusión cromática que guardaba estrecha relación con las intencionalidades comunicacionales y la influencia del lenguaje gráfico en los jóvenes participantes. A continuación, se recopilan algunos de los resultados derivados de la práctica colaborativa de creación visual, desde referentes, gráficos, perceptivos y con intencionalidades comunicativas que exteriorizan los intereses del grupo que representan (Figura 3 , Figura 4, Figura 5, Figura 6 y Figura 7).

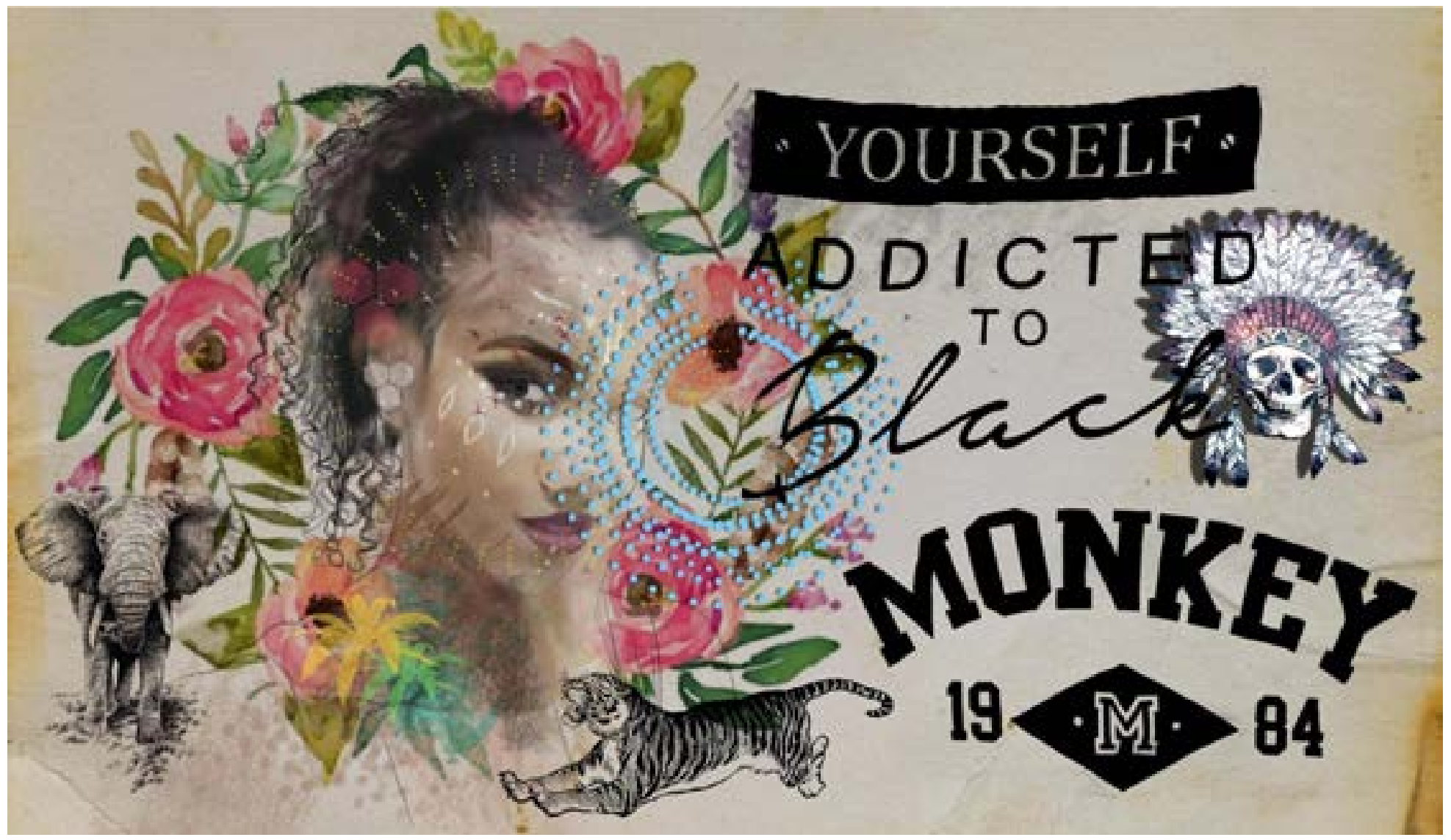

Figura 3. Composiciones visuales propuestas por medio de la co-creación. Fuente: Elaboración propia. 


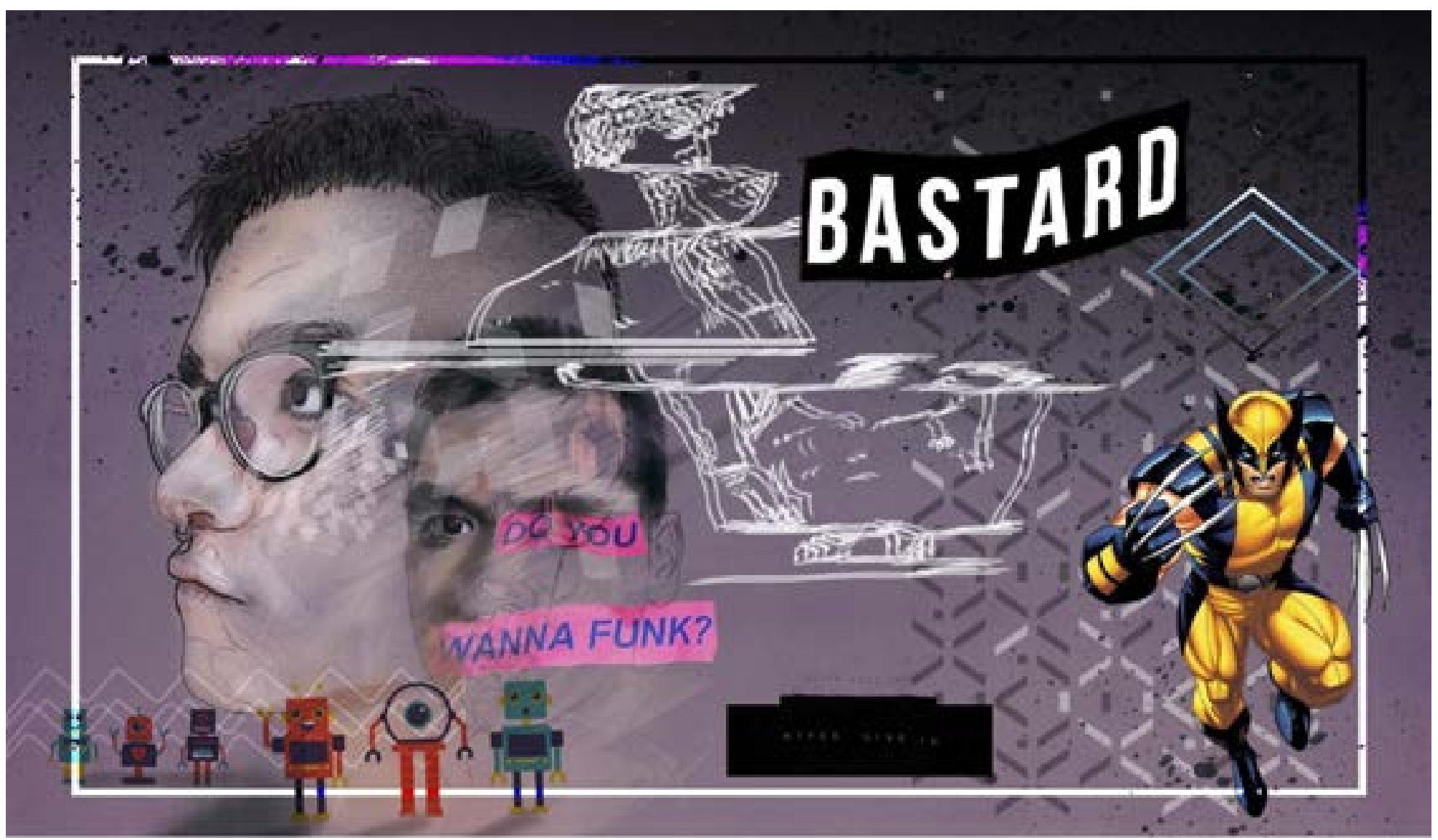

Figura 4. Composiciones visuales propuestas por medio de la co-creación. Fuente: Elaboración propia.

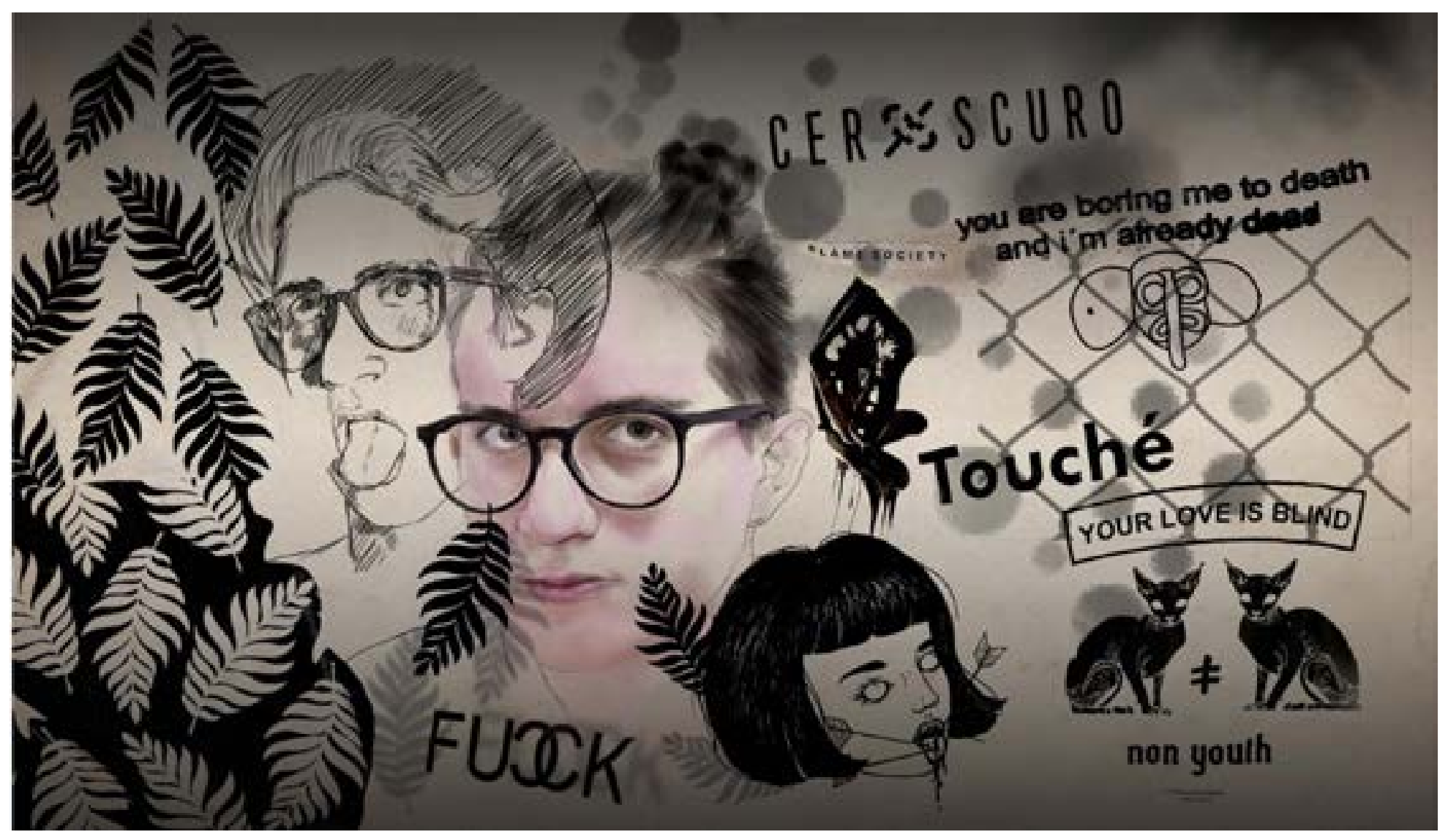

Figura 5. Composiciones visuales propuestas por medio de la co-creación. Fuente: Elaboración propia. 


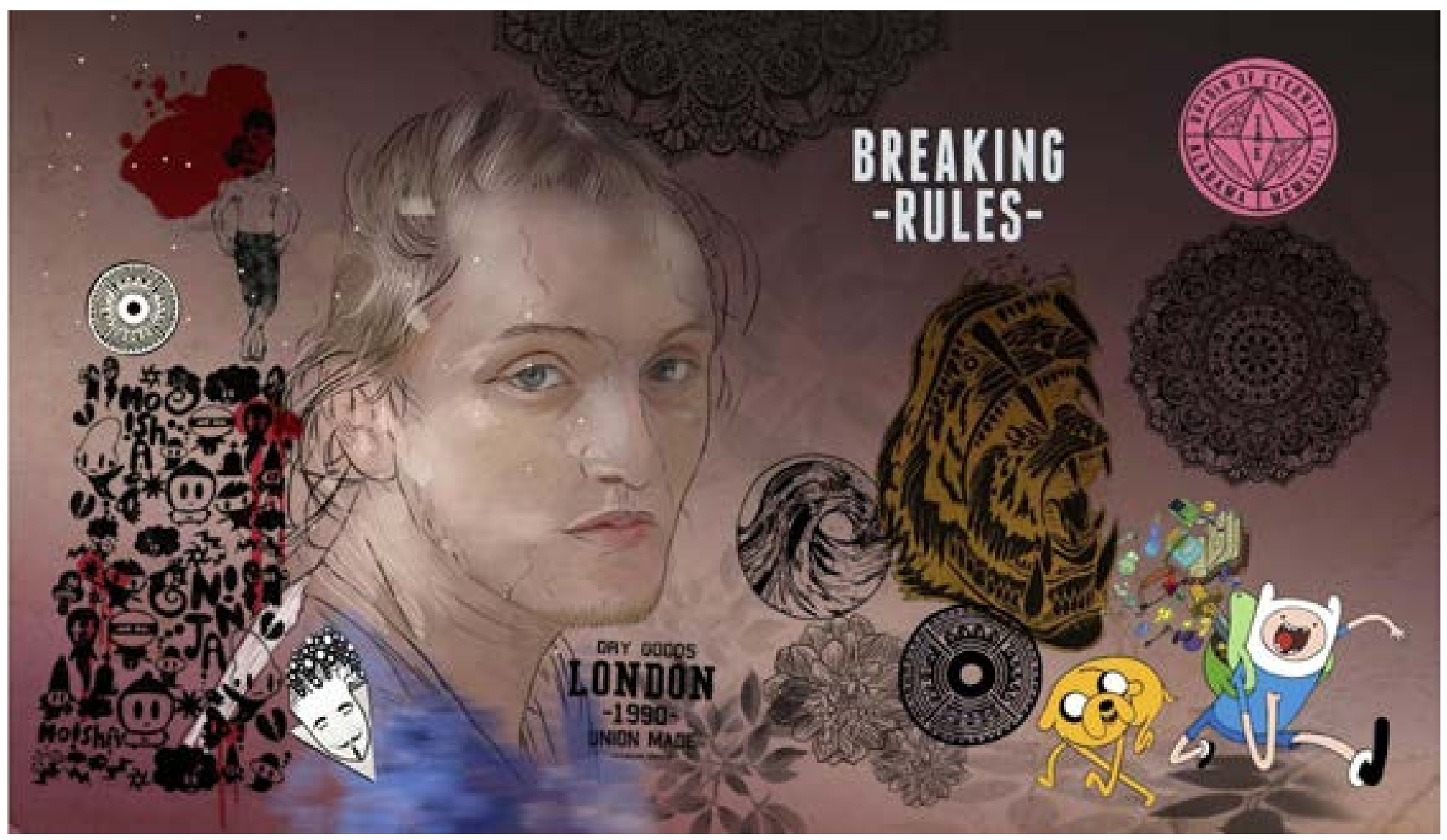

Figura 6. Composiciones visuales propuestas por medio de la co-creación. Fuente: Elaboración propia.

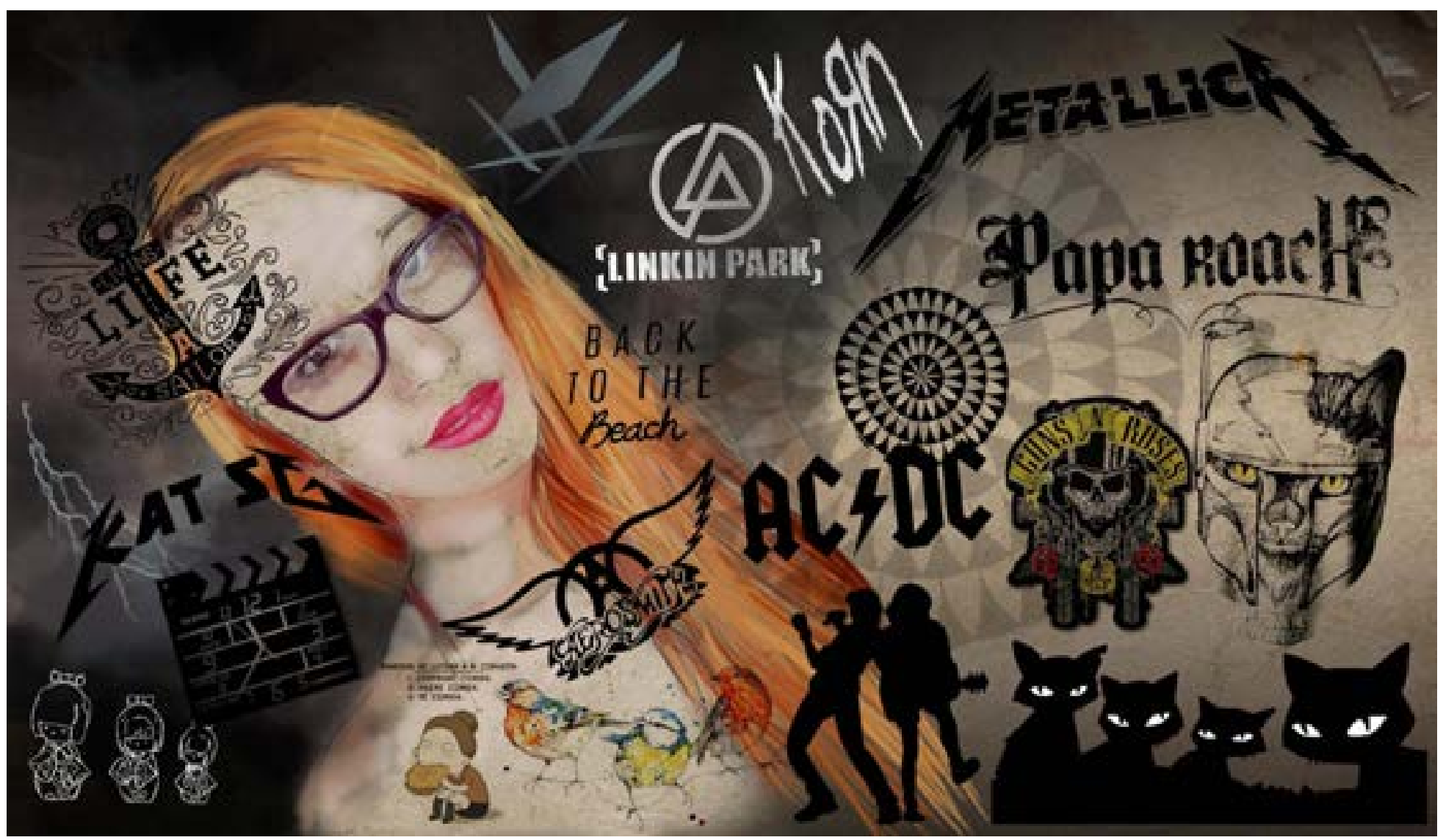

Figura 7. Composiciones visuales propuestas por medio de la co-creación. Fuente: Elaboración propia. 
Algunos de los resultados visuales que se derivaron del ejercicio de co-creación, en los cuales diversas posturas, intereses, experiencias y lenguajes se integraron para representar las estéticas propias de los sujetos de estudio, fueron socializados a la comunidad de Pereira en el Colombo Americano de Pereira, mediante las "Exposiciones en corto", un evento concertado con el Ministerio de Cultura, el Programa Nacional de Concertación Cultural en el Marco del Corto Circuito, Escenarios para el Arte a finales del año 2017 (Figura 8). La gran acogida del evento permitió una difusión amplia y dialogar con jóvenes que se veían reflejados en dichas composiciones visuales.

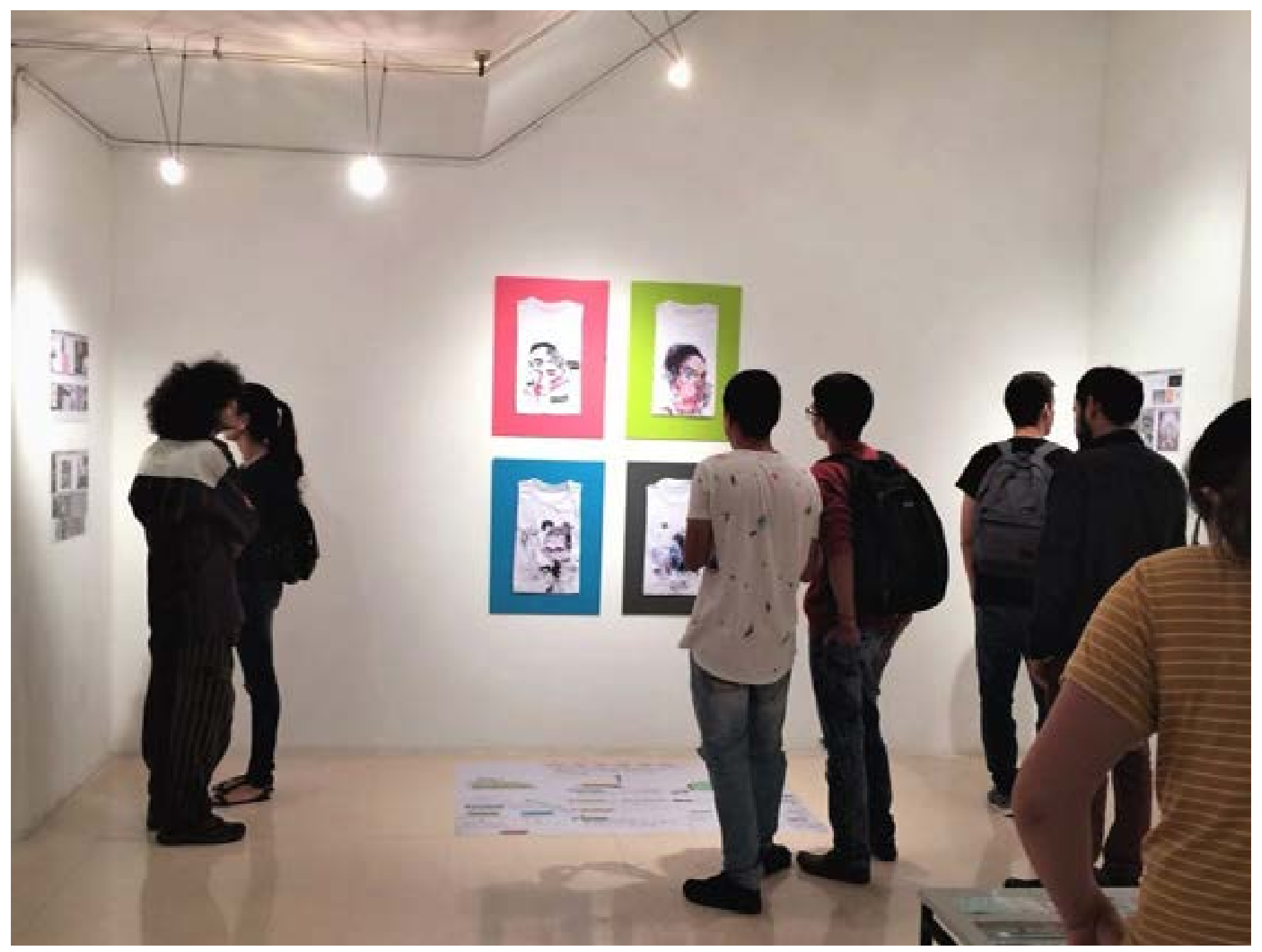

Figura 8. Exposición pública de la obra de creación Fuente: Elaboración propia.

Finalmente, resulta importante para la investigación formativa en diseño, concluir los procesos de recolección de información y análisis en trayectos de creación que permitan la interacción entre docentes y estudiantes, con el ánimo de construir procesos de formación sólidos, pero que, a la vez, permitan la exploración conjunta en el ejercicio de la creación. Donde a través de la investigación- creación tenga igual relevancia tanto la obra como el proceso creativo, para contribuir a la experiencia humana desde construcciones de sentido. 


\section{REFERENCIAS}

Arcangel. (2018). Arcangel + Bad Bunny - Original. [Official Video]. [Video de youtube]. Disponible en https://youtu.be/zkfyNvdMyYI?t=96

Aristóteles. (1873). La política. Madrid: FV Éditions.

Bourdieu, P. (2006). La Distinción, criterios y bases sociales del gusto. Madrid: Taurus.

Cardi B. (2018). Cardi B, Bad Bunny \& J Balvin - I Like It [Official Music Video]. [Video de youtube]. Disponible en https://youtu.be/xTINMmZKwpA?t=98

Carballo, P. (2011). Claves para entender las nuevas sensibilidades: Estudios sobre producciones culturales juveniles en Costa Rica. Revista latinoamericana de ciencias sociales, niñez y juventud, 7 (2), 1331-1347. Recuperado de http://biblioteca.clacso. edu.ar/Colombia/alianza-cinde-umz/20131127114206/art.PriscillaCarballo.pdf

Entwistle, J. (2002). El cuerpo y la moda Una visión sociológica. Barcelona: Paidós.

Glover, H. (2017). De la hoja de parra al bikini: la moda como soporte de comunicación social. [Tesis doctoral]. Universidad Complutense de Madrid, Madrid, España. Disponible en https://eprints.ucm.es/41612/

Goffman, E. (1959). La presentación de la persona en la vida cotidiana. Buenos Aires: Amorrortu editores.

Hernández, R. (2006). Argumentos para una metodología de dato visual. Cinta de Moebio, (26), 196-206. Disponible en https:/www.moebio.uchile.cl/26/hernandez. html

Iglesias, J. (2015). El papel de las marcas de moda en la construcción de la identidad personal. [Tesis Doctoral]. Universitat Ramon Llull, Catalunya, España. Recuperado de https:/www.tdx.cat/bitstream/handle/10803/369847/Tesi_Jordi_Iglesias. pdf?sequence=1\&isAllowed=y

Leroi-Gourhan, A. (1971). El gesto y la palabra. Caracas: Ediciones de la Biblioteca.

Lipovetsky, G. (1990). El imperio de lo efímero. La moda y su destino en las sociedades modernas. Barcelona: Anagrama.

Lozano, M. C. y Alvarado, S. V. (2011). Juicios, discursos y acción política en grupos de jóvenes estudiantes universitarios de Bogotá. Revista Latinoamericana de Ciencias Sociales, Niñez y Juventud, 1(9), 101-113. Disponible en http://revistaumanizales. cinde.org.co/rlcsnj/index.php/Revista-Latinoamericana/article/view/346

Mandoki, K. (2006). Prosaica II: Prácticas estéticas e identidades sociales. México D.F.: Siglo XXI.

Migliaccio, M. (2013). Fundamentos antropológicos de la moda: Magnanimidad y Elegancia. [Tesis doctoral]. Universidad de Navarra, Pamplona, España. Disponible en https://dadun.unav.edu/handle/10171/29186

Muller, J. (2008). 100 clásicos del cine. Madrid: Taschen. 
Onofre-Chaves, D. (2017). La investigación en estilos de vida en psicología de consumidor. Cultura, Educación y Sociedad, 8(1), 51-70. http://dx.doi.org/10.17981/cultedusoc.8.1.2017.04

Sanders, E.-N. \& Stappers, P. J. (2008). Co-creation and the new landscapes of design. Co-design, 4(1), 5-18. https://doi.org/10.1080/15710880701875068

Sanjurjo, B. (2001). La serigrafía como medio de expresión artística: (posibilidades técnicas). [Tesis doctoral]. Universidad complutense de Madrid, Madrid, España. Disponible en https://eprints.ucm.es/1720/

Santaella, M. (2006). La evaluación de la creatividad. Sapiens, 7(2), 89-106. Disponible en http://ve.scielo.org/scielo.php?script=sci_arttext\&pid=S1317-58152006000200007\&ln $\mathrm{g}=\mathrm{es} \& \mathrm{tlng}=\mathrm{es}$

Trindade, E. y Da Silva, J. (2010). Antropología, comunicación e imágenes: alternativas para pensar la publicidad y el consumo en la contemporaneidad. Pensar la Publicidad. Revista Internacional de Investigaciones Publicitarias, 3(1), 203-218. Disponible en https://revistas.ucm.es/index.php/PEPU/article/view/PEPU0909120203A

WGSN. (2016). Iconoclastas jóvenes. [Online]. Recuperado de https://www.wgsn.com

Erika María Gómez Bermeo es Diseñadora de Modas y Textiles de la Fundación Universitaria del Área Andina (Colombia). Especialista en Educación con Nuevas Tecnologías de la Universidad Autónoma de Bucaramanga (Colombia). Magíster en Estética y Creación de la Universidad Tecnológica de Pereira (Colombia). https://orcid.org/0000-0003-31801049

Edwin Javier Morales Perdomo es Licenciado en Artes Visuales. Magíster en Estética y Creación de la Universidad Tecnológica de Pereira (Colombia). Magíster en Producción Artística y Especialidad en Arte y Tecnología de la Universidad Politécnica de Valencia (España). https://orcid.org/0000-0001-6311-8186

Andres Felipe Roldán García es Diseñador Industrial de la Universidad Nacional de Colombia (Palmira, Colombia). Especialista en Gestión de la Innovación Tecnológica de la Universidad del Valle (Cali, Colombia). Magíster en Ingeniería Industrial de la Universidad del Valle (Cali, Colombia). Magister en Estética y Creación de la Universidad Tecnológica de Pereira (Pereira, Colombia). Doctor en Diseño y Creación de la Universidad de Caldas (Manizales, Colombia). https://orcid.org/0000-0002-1137-9664 